\section{Attendance of the RMO at Tribunals}

Sir: I would like to bring to attention particular problems encountered when acting as an independent psychiatrist at Mental Health Review Tribunals, particularly when instructed in such matters by the patient's solicitor, in cases involving patients detained under Section 37 and Section 41 of the Mental Health Act 1983.

In cases, far from straightforward, 1.e. where the diagnosis has been subject to dispute and the patient's care plan is at issue, those instructing me have made arrangements for me to be available at the Tribunal to give verbal evidence. I am usually given a hearing date rather than the date being subject to negotiation. The routine of the Tribunal office for those who arrange Tribunals is to liaise with the responsible medical officer (RMO) so that he is present at the hearing. Conflicts of interest have arisen, apparently, in some cases which have prevented the RMO from at tending the Tribunal, undermining the potential for exploring points at issue and putting the applicant and his legal adviser at a considerable disadvantage.

It is my opinion, particularly in restricted cases, that the RMO as the person responsible for the patient's ongoing detention, should always be avallable to give evidence at the Tribunal. I appreciate that conflicts over use of time will arise but there is no greater requirement on a doctor's time than attending a Tribunal considering the further management of the detained patient.

I have noted the increasing use of the subpoena and similar methods to ensure the presence of expert witnesses in a variety of settings in the last two to three years. It will now be my advice to those instructing me to prepare independent reports for Mental Health Review Tribunals that the RMO should be routinely subpoenaed where the case involves a patient who is detained and subject to a restriction order so that a fair balance of opinion can be heard by the Tribunal prior to their reaching decisions, if this process of appeal is not to be devalued.

PETER WOOD, 9 Eldon Place, Manningham Lane, Bradford BD1 3AZ

\section{Propofol and electroconvulsive therapy}

Sir: In 1988 reports first appeared suggesting propofol to be unsuitable for electroconvulsive therapy (ECT) anaesthesia as it significantly reduced seizure duration. This finding has been confirmed in subsequent studies. Guidelines laid down by The Royal College of Psychiatrists (1989) made no reference to propofol; however, their recent ECT video clearly recommends that propofol should not be used.
In December 1991 propofol was still being used for ECT anaesthesia in East Suffolk. We conducted a retrospective case-note analysis, with the aim of describing the local anaesthetic prescribing policy, and additionally sought to determine whether compared with methohexitone, propofol anaesthesia was associated with more unsatisfactory ECT applications as described in the College guidelines (absent seizures, doubtful seizures, unilateral seizures, focal seizures and very brief seizures).

Local policy was to stimulate patients initially with $275 \mathrm{mC}$, from Ectron series 5 apparatus, subsequently adjusting the stimulus depending on the response determined by simple observation and stop-watch timing. One hundred consecutive courses of ECT ( 1120 applications) were investigated in 95 patients aged between 26 and 93 years (mean 63.3 years); $85 \%$ of courses were administered to patients suffering from depressive illness. Patients were anaesthetised with either methohexitone (mean dose $69.2 \mathrm{mg}$ ) or propofol (mean dose $53.5 \mathrm{mg}$ ); 165 applications (15\%) were with propofol anaesthesia. Thirtynine patients received at least one propofol anaesthetic. Of this group, $26 \%$ were anaesthetised predominantly with propofol but in only one patient was propofol exclusively used. In all cases suxamethonium (mean dose $43.8 \mathrm{mg}$ ) was used. No patients received atropine.

The observed proportion of unsatisfactory applications was higher $(27 \%)$ in propofol anaesthetised treatments than methohexitone anaesthetised treatments (12\%). This was significant $\left(\chi^{2}=25.175, P<0.0005\right.$, one-tailed). Patients receiving propofol did not differ significantly from those exclusively receiving methohexitone, in age, drug consumption, physical health or mode of ECT application.

In summary, propofol was regularly being used for ECT anaesthesia in late 1991 and was associated with an increased rate of unsatisfactory seizures. In some districts it may still be in regular use. Psychiatrists responsible for ECT should ensure that their anaesthetist colleagues are aware of propofol's disadvantages.

Royal COLlege of PSYchiatrists (1989) The Practical Administration of Electroconvulstue Therapy. London: Gaskell.

P.W. BenTHAM, The Queen Elizabeth Psychiatric Hospital, Edgbaston, Birmingham, B15 IQ2; and L.F. Callinan, The Old Manor Hospital, Witon Road, Salisbury, SP2 7EP

\section{Antipsychotic medication use in relation to BNF guidelines}

Sir: Two recent audits of antipsychotic medication prescribing in regional secure units highlighted regimes that did not always meet BNF 
guidelines (Gill, 1993; Stanley \& Doyle, 1993). Prescribing above BNF recommended maximum daily doses was of particular concern $(6.5 \%$ and $50 \%$ of patients respectively). As results from these audits may not relate to the majority of psychiatric in-patients, we examined the prescribing of antipsychotic medication in a general psychiatric hospital over a 24 hour period in 1993. A similar audit had been performed two years previously.

Of 77 in-patients in general psychiatry wards. 55 received an antipsychotic medication. One patient received more than the BNF recommended maximum daily dose and two others could have done if all prescribed PRN doses were given. Six patients received more than one antipsychotic; two by more than one route. Of 42 in-patients in old age psychiatry wards (functional mental illness), 21 received ant1psychotic medication. None were given or prescribed over BNF recommended maximum daily doses although there are often no specific guidelines for elderly people. Three patients recetved more than one type of oral antipsychotic medication.

Two years previously, 63 of 113 general and old age psychiatry in-patients received antipsychotics over a similar 24 hour period. One patient received an antipsychotic over recommended BNF limits. Eleven received more than one antipsychotic medication; seven by more than one route. Prescription of antipsychotic medication in excess of BNF guidelines is not common in this general psychiatric hospital setting $(<1 \%)$, perhaps because of the addition of benzodiazepines for sedation or lower doses of more than one antipsychotic. Although both practices are probably safer alternatives, it is not clear how to assess the risk of using multiple neuroleptics.

'Chlorpromazine equivalents' are often used to estimate the additive risk of multiple neuroleptics (Stanley \& Doyle, 1993). However, these are based on antipsychotic activity or dopamine receptor affinity, whereas BNF limits are principally related to the side effect profile. If one's concern with departing from BNF guidelines is from a medico-legal point of view (Gill, 1993), it may be of interest that there is no BNF recommended maximum daily dose for trifluoperazine.

Giu, D. (1993) Audit of antipsychotic use in relation to BNF guidelines on dose, route and polypharmacy. Psychtatric Bulletin, 17, 773-774.

Stanley, A. \& Doyle. M. (1993) Audit of above BNF dosage medication. Psychiatric Bulletin. 17, 299-300.

BOBBy TORKINGTON, SHELlEY HOGG, GUY POWELL, CHRISTINE MAIN and ANDREW BARKER, St Ann's Hospital, Canford Cliffs, Poole BH13 7LN
Age and sex difierences in general practice benzodiazepine prescription in United Kingdom

Sir: Around 10\% of people in Europe use tranquilisers, the majority being prescribed by general practitioners (Woods et al, 1987). However, there is little information on the circumstances of such prescriptions. We report on a survey of benzodiazepine prescriptions in a general practice in East London over a three month period. Of the total number of patients, 3.6\% (302/8253) received benzodiazepines, $87 \% \quad(7180 / 8253)$ being repeat prescriptions. There was an agerelated increase in the prescription; $0.4 \%(18 /$ $3805)$ in the 18-44 year age range, $3 \%(75 / 2501)$ in 45-65 year group and 10.7\% (209/1947) aged over 65 years.

The age-related difference was apparent in repeat prescriptions as well; one in eight $(25 / 209)$ of those over 65 years had not had their medication reviewed in the preceding year and one in $23(9 / 209)$ in the preceding three years. Only $4 \%$ $(3 / 75)$ from the 45-65 year group and none aged 18-44 years fell into this category.

After correcting for sex distribution of the total population, women aged 45 to 65 years were twice as likely, and those over 65 years three times more likely, to receive benzodiazepines than men. The over-representation of elderly women was also observed by van der Waals et al. 1993. However, women were four times more likely to have their prescription reviewed in the preceding year.

Learoyd (1972) found that, among psychogeriatric patients, $16 \%$ presented with disorders attributable to side effects of psychotropic drugs and that in 20\% this was the reason for hospital admission, the most frequently implicated agent being tranquilisers. They also cause drowsiness and unsteadiness resulting in increased likelihood of falls and fractures.

It seems that elderly patients who are most vulnerable to developing pharmacological interactions and central nervous system side effects are the ones more likely to receive benzodiazepines. Our findings suggest the need for more careful monitoring, given that $87 \%$ of the benzodiazepine prescriptions were repeats, and as many as one in eight of those over 65 years were receiving them without review of the need for continuation. In addition to clinical concern, this has implications for costing, the cost of medication and of clinical morbidity and hospital admission attributable to side effects of this medication.

LEAROYD, B.M. (1972) Psychotropic drugs and elderly patient. Medical Journal of Australla, 1, 1131-1133.

VAN DER WALS. F.W.. MOHRS, J. \& FOETS, M. (1993) Sex differences among recipients of benzodiazepines in Dutch general practice. British Medical Journal, s07, 363-366. 